\title{
STRENGTHENING FACTORS AIND PHASE RELATION IN Ni-Cr-W ALLOYS DEVELOPED FOR NUCLEAR STEELMAKING
}

\author{
R. Tanaka, M. Kikuchi, T. Matsuo, S. Takeda*, \\ II. Nishikawa*, T. Ichihara*, and M. Kajihara* \\ Department of Metallurgical Engineering \\ Tokyo Institute of Technology, Tokyo, 152, Japan \\ * Graduate Student, Tokyo Institute of Technology
}

Isothemal sections of a $N i-C r-W$ temamy equilibrium phase diagram were experimentalzy determined at 1000 and $1100^{\circ} \mathrm{C}$. Based on the experimental tieIines, a computation of equilibrium between foc $\gamma$ and bce a phase was carried out in order to determine the solubitity of tungsten in fec nickel-chromium alzoys at various temperatures.

Creep rate and creep muture stength were measured in a series of five Ni-20 pet Cr alloys containing different comount of tungsten up to twenty per cent. creep tests were conducted at 900 and $1000^{\circ} \mathrm{C}$ in the stress range between 15 and $59 M$ a in vacum and in helium as well as in air. The creep muture strength increased and the steady state creep rate decreased with increasing tungsten concentration. Factors affecting solid solution strengthening due to tungsten were clarified, using the first four alzoys with less thur fisleen pex cent tungsten. In the alzoy with twenty per cent tungsten, a tungsten-pich bce $\alpha_{2}$ phase precipitated at the grain boundary during testing. The precipitation of the $\alpha_{2}$ phase at the grain boundary together with the maximum solubility of tungsten substantially improved the creep properties of the Ni-20 pet Cr alioys with tungsten. The precipitation of the $\alpha_{2}$ phase eliminated the environmental susceptibility inherent to the single phase alzoys based on the $\mathrm{Ni}-\mathrm{Cr}-\mathrm{W}$ system in the reduced oxygen potential. 


\section{INTRODUCTTON}

It has widely been realized that high temperature gas cooled reactors must be operated at temperatures highcr than $1000^{\circ} \mathrm{C}$ to use nuclear energy for steelmaking. One of the difficulties to utilize the high temperature helium gas heated at around $1000^{\circ} \mathrm{C}$ by the HTGR for nuclear steelmaking is that there exists no suitable commercial superalloys for intermediate heat exchanger tubes at present. To overcome this difficulty, Engineering Research Association of Nuclear Steelmaking supportcd by the Japanese government started in 1973 a research program, among other five programs, to develop tubular alloys with a creep rupture strength of higher than $1 \mathrm{kgf} / \mathrm{mm}^{2}$ ( $9.8 \mathrm{MPa}$ ) at $100000 \mathrm{~h}$ in an HTGR helium atmosphere at $1000^{\circ} \mathrm{C}(1)$. A few superalloys based on a $\mathrm{Ni}-\mathrm{Cr}-\mathrm{W}$ alloy system have already been developed(2). These superalloys, with minor adjustment of the chemical compositions, are expected to fulfill the above requirement for the intermediate heat exchanger tubes. Unfortunately, however, only very limited experimental investigations have so far been carried out on both phase relation in a nickel-rich corner of the $\mathrm{Ni}-\mathrm{Cr}-\mathrm{W}$ alloy system and detailed factors affecting the high strength of these alloys. The study on these subjects is highly important to improve the strength of the newly developed superalloys through heat-treatment and chemical composition.

There are, therefore, two objectives in this study. The first objective is to determine the phase relalion in the $\mathrm{Ni}-\mathrm{Cr}-\mathrm{W}$ system, including solubility of tungsten in nicke1rich nickel-chromium alloys. The second is to clarify the strengthening factors in both single- and multi-phase $\mathrm{Ni}-\mathrm{Cr}-\mathrm{W}$ alloys. In addition to these, the environmental effect has been studied on creep properties of these alloys.

\section{PHASE RELATION}

Isothermal sections of the $\mathrm{Ni}-\mathrm{Cr}-\mathrm{W}$ ternary equilibrium phase diagram were experimentally determined at 1000 and $1100^{\circ} \mathrm{C}$. Emphasis was placed upon the nickel-rich corner of the $\mathrm{Ni}-\mathrm{Cr}-\mathrm{W}$ system. Six different alloys with multi-phase compositions were arc-melted in an argon atmosphere from high purity elemental materials. Button ingots were homogenized in purified hydrogen gas at $1250^{\circ} \mathrm{C}$ for $50 \mathrm{~h}$. Specimens cut from the homogenized ingots were sealed separately in evacuated silica capsules and equilibrated at 1000 and $1100^{\circ} \mathrm{C}$ for 
2000 and $I 000 \mathrm{~h}$, respectively. Phases in the equilibrated specimens were identified in terms of X-ray powder diffraction. The chemical composition of each phase was analyzed and tie-lines among the constituent phases were determined by means of the electron probe microanalysis.

The results at $1000^{\circ} \mathrm{C}$ are illustrated as an isotherma 1 section in Fig. I. Two phase equilibrium between fcc $\gamma$ nickel-rich and bcc $\alpha_{2}$ tungsten-rich phase, and three phase equilibrium among $\gamma, \alpha_{2}$ and $\sigma$ phase were determined experimentally. Unlike the earlier phase diagram constructed by Kornilov and Budberg(3), a $\gamma /\left(\gamma+\alpha_{2}\right)$ phase boundary extends near to a nicke1-chromium binary side. Both $\gamma /(\gamma+\sigma)$ and $\gamma /\left(\gamma+\alpha_{1}\right)$ phase boundaries, where a bcc chromium-rich phase designated $\alpha_{1}$, should, therefore, be substantially narrower than those in the earlier diagram.

A computation of equilibrium between the fcc $\gamma$ and the bcc $\alpha$ phase in the $\mathrm{Ni}-\mathrm{Cr}-\mathrm{W}$ system was carried out in order to determine the solubility of tungsten in fcc nickel-chromium alloys at other temperatures than 1000 and $1100^{\circ} \mathrm{C}$. Following the method developed by Kaufman and Bernstein(4), both $\gamma$ and $\alpha$ solid solutions were assumed to be sub-regular. All the interaction parameters except the ones in a fcc tungstenchromium binary solution have already been evaluated by Kaufman and Nesor $(5,6,7)$. The latter parameters were selected to be fitted to the experimental tie-lines between $\gamma$ and $\alpha_{2}$ at 1000 and $1100^{\circ} \mathrm{C}$. In Fig.2 are illustrated the calculated solubility curves at the nickel-rich corner in the $\mathrm{Ni}-\mathrm{Cr}-\mathrm{W}$ system. Heavy and thin lines indicate the calculated results in the present study and those proposed experimentally by Kornilov and Budberg(3), respectively. A single phase region of the $\gamma$ phase is actually smaller than that in the earlier diagram. The solubility of tungsten in fcc nicke1-chromium alloys increases moderately with increasing temperature. The above computation was extended to $\mathrm{Ni}-\mathrm{Cr}-\mathrm{W}-\mathrm{Mo}$ and $\mathrm{Ni}-\mathrm{Cr}-\mathrm{W}-\mathrm{C}$ quaternary systems to determine the solubility of tungsten in the nicke1-rich fcc $\gamma$ phase(8).

\section{STRENGTHENING FACTORS}

Creep rate and creep rupture strength were measured in a series of five $\mathrm{Ni}-20$ pct $\mathrm{Cr}$ alloys containing different amount of tungsten up to twenty per cent. Nominal concentration of tungsten in these alloys was $0,5,10,15$ and 20 pet. A11 the specimens were fully solution-treated in the tempcrature range from 1100 to $1250^{\circ} \mathrm{C}$ to obtain a mean grain size of 
$200 \mu \mathrm{m}$. Creep tests were conducted at 900 and $1000^{\circ} \mathrm{C}$ in the stress range between 15 and $59 \mathrm{MPa}$ in vacuum and in helium as well as in air. The vacuum pressure during testing was $7 \times 10^{-3} \mathrm{~Pa}$. The helium with the purity of 99.998 pct was supplied during testing at a flow rate of $3 \times 10^{-2} \mathrm{~m} / \mathrm{s}$. The detailed experimental procedure has been reported in the previous paper(9).

The creep rupture strength increased and the steady state (minimum) creep rate decreased with increasing tungsten concentration. The steady state creep rates at $1000^{\circ} \mathrm{C}$ in air are plotted as a function of stress in Fig. 3, A11 the alloys followed a power law stress dependence. It is to be noted that the stress exponent, $n$, of the alloy with twenty per cent tungsten $(n=5.7)$ is substantially larger than that $(n=4.7 \pm 0.5)$ of the other four alloys with less than fifteen per cent.

From the results in the previous chapter, tungsten is expected to be in solution even during testing in the first four alloys with less than fifteen per cent tungsten. Assuming that all the five alloys were single phase, the steady state creep rate, $\dot{\varepsilon}_{S}$, was analyzed, to delineate factors affecting solid solution strengthening due to tungsten, in terms of the following equation(10),

$$
\dot{\varepsilon}_{S}=A \gamma^{\mathrm{m}}(\sigma / \mathrm{E})^{5} \mathrm{D} \text {, }
$$

where $\gamma$ is the stacking fault energy, $\sigma$ is the applied stress, $E$ is the elastic modulus, $D$ is the appropriate diffusivity and $A$ is a constant. It is true that the value of $m$ is usually assumed to be constant $(10,11)$; in this case, however, m depended on $\gamma$ and decreased from 3.5 to 1.0 with $\gamma$ decreasing from 0.11 to $0.02 \mathrm{~J} / \mathrm{m}^{2}$. Figure 4 shows the contribution of $Y, E, D$ and $A$, separately, to the strengthening in the steady state creep rate at $1000^{\circ} \mathrm{C}$ at the stress of $19.6 \mathrm{MPa}$ in air. The overall strength increase due to tungsten up to fifteen per cent can be seen, from this figure, to be ascribed mainly to the increase in $\mathrm{E}$ and the decrease in $\mathrm{D}$. It should be noted that the steady state creep rate of the alloy with twenty per cent tungsten deviates far below the curve extrapolated from that of the alloys with less than fifteen per cent.

Microstructures of the ruptured specimens of the alloys with fifteen and twenty per cent tungsten are shown in Fig. 5. No second phase was observed in the alloys with less than fifteen per cent tungsten, as is shown in an optical micrograph in Fig. 5(a). In contrast to this, as is expected from the previous chapter, precipitation took place at the grain bound- 
ary in the alloy with twenty per cent tungsten, as is shown in Fig. 5(b). These precipitates were identified as the $\alpha_{2}$ phase by both X-ray powder diffraction and the electron probe microanalysis. Appreciable fraction of all the grain boundaries was covered by the $\alpha_{2}$ precipitates. lhis is best illustrated in Fig. 5(c), which is a scanning electron micrograph of the intergranular fracture surface of the alloy specimen with twenty per cent tungsten ruptured at $900^{\circ} \mathrm{C}$ at the stress of $29.4 \mathrm{MPa}$ in vacuum. It is to be noted that the size of the $\alpha_{2}$ precipitates with spherical or ellipsoidal shape remained on the order of $1 \mu \mathrm{m}$, even after the exposure at $900^{\circ} \mathrm{C}$ for $1000 \mathrm{~h}$. Grain boundary precipitation of the $\alpha_{2}$ phase without any intragranular precipitation caused the decrease in the creep rate and the increase in the creep rupture strength as well as the creep ductility.

In Fig. 6 are illustrated creep rate curves for a11 the alloy specimens crept at the stress of $19.6 \mathrm{MPa}$ at $1000^{\circ} \mathrm{C}$ in air. Unlike the curves for the first four specimens with less than fifteen per cent tungsten, the curve for the alloy with twenty per cent tungsten does not indicate the steady state. Instead, the creep rate gradually decreases with testing time until the onset of the tertiary stage. The gradual decrease in the creep rate corresponds to the gradual increase in the amount of the precipitates at the grain boundary. The precipitation of the $\alpha_{2}$ phase was slow enough to affect the stress dependence of the creep rate as well as that of the rupture life. At high stress for short rupture life, the specimen failed before much precipitation took place; while at low stress for long rupture life, the specimen was gradually strengthened by the precipitation of the $\alpha_{2}$ phase at the grain boundary, as is shown in Fig. 6. The larger stress exponent in the alloy with twenty per cent tungsten can be attributed to the slow precipitation of the $\alpha_{2}$ phase. It is reasonably presumed that the creep rupture stress increases with increasing the fraction of coverage by the $\alpha_{2}$ precipitates.

In the single phase alloys with less than fifteen per cent tungsten, the rupture life became shorter and the steady state creep rate became larger by a factor of about five in both vacuum and helium than those in air. Furthermore, ductility reduced to half in the single phase alloys in vacuum as well as in helium. The single phase alloys without the $\alpha_{2}$ precipitates are quite susceptible to the reduced oxygen potential. In the two phase alloy with the $\alpha_{2}$ precipitates at the grain boundary, however, the environmental atmosphere did not affect the creep properties; that is, the steady state 
creep rate, the creep rupture strength and the rupture ductility in vacuum and in helium were the same as those in air.

\section{CONCLUSIONS}

The precipitation of the bcc tungsten-rich $\alpha_{2}$ phase at the grain boundary not only strengthens further the fcc Ni-Cr-W alloys with high strength, it also reduces the susceptibility inherent to the $\mathrm{fcc}$ single phase $\mathrm{Ni}-\mathrm{Cr}-\mathrm{W}$ alloys in the reduced oxygen potential. The precipitation strengthening due to the $\alpha_{2}$ precipitates at the grain boundary is, therefore, a very promising way to improve the $\mathrm{Ni}-\mathrm{Cr}-\mathrm{W}$ base superalloys developed for nuclear steelmaking. The equilibrium phase diagram presented in this paper should be used in selecting heat-treatment and chemical composition for modifying the Ni-Cr-W base superalloys.

\section{REFERENCES}

(1) T.Sugeno, K.Shimokawa and K.Tsuruoka: Iron Steel Engineer, Vo1.53, No.11, 1976, p.40.

K.Shimokawa: Trans. Iron Steel Inst. Japan, Vol.19, No.5, 1979 , p. 291.

(2) Y.Hosoi: Report of the 123rd Committee on Heat-Resisting Metals and Alloys, Vo1.18, 1977, p,177.

(3) I.I.Kornilov and P.B.Budberg: Zh. Neorgan. Khim., Vo1.1, 1957, p. 860 .

(4) L.Kaufman and H.Bernstein: "Computer Calculation of Phase Diagrams," Academic Press, New York, 1970.

(5) L.Kaufman and H.Nesor: Z. Metallkde., Vol.64, 1973, p.249.

(6) L.Kaufman and H.Nesor: Cand. Met. Quart., Vo1.14, 1975, p. 221 .

(7) L.Kaufman and H.Nesor: Met. Trans. A, Vo1.6A, 1975, p. 2123.

(8) M.Kajihara: Master of Engineering Thesis, Tokyo Institute of Technology, 1980.

(9) H.Nishikawa, T.Ichihara, T.Matsuo and R. Tanaka: Report of the 123rd Committee on Heat-Resisting Metals and Alloys, Vol.20, 1979, p.13.

(10) C.R.Barrett and O.D.Sherby: Trans. TMS-ATME, Vo1.233, 1965 , p. 1116.

(11) K.Yamada and H.Suto: Report of the 123rd Committee on Heat-Resisting Meta1s and Alloys, Vo1,13, 1972, p.251. 


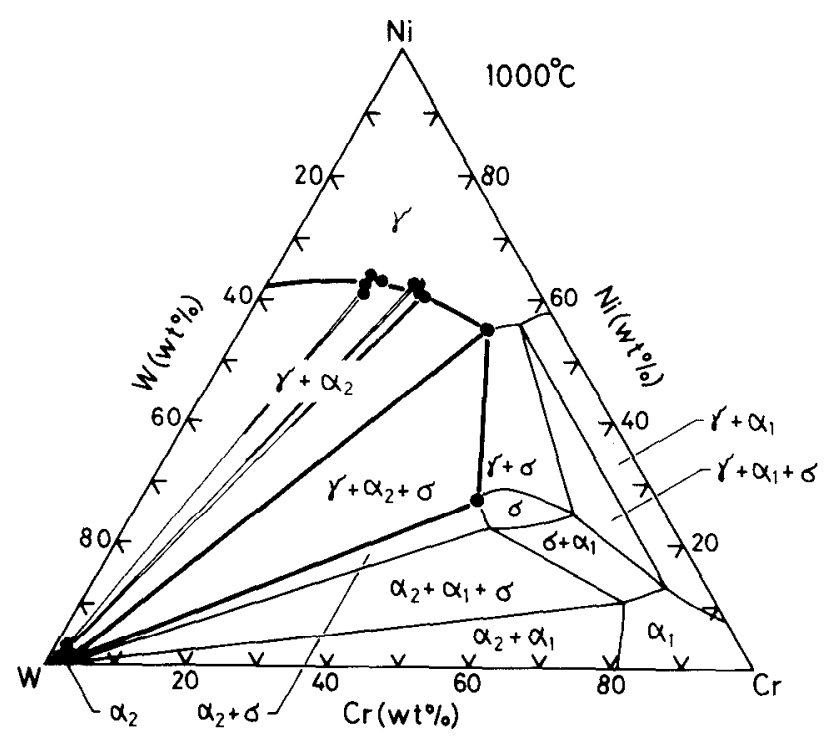

Fig. 1 Isothermal Section of $\mathrm{Ni}-\mathrm{Cr}-\mathrm{W}$ System at $1000^{\circ} \mathrm{C}$.

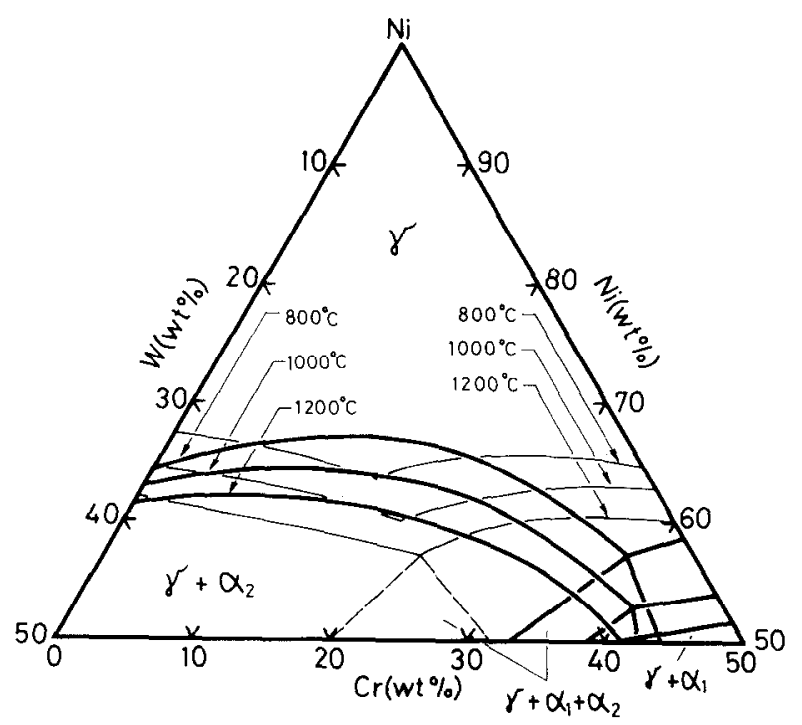

Fig. 2 Calculated Phase Boundaries of $\gamma /\left(\gamma+\alpha_{1}\right)$ and $\gamma /\left(\gamma+\alpha_{2}\right)$. 

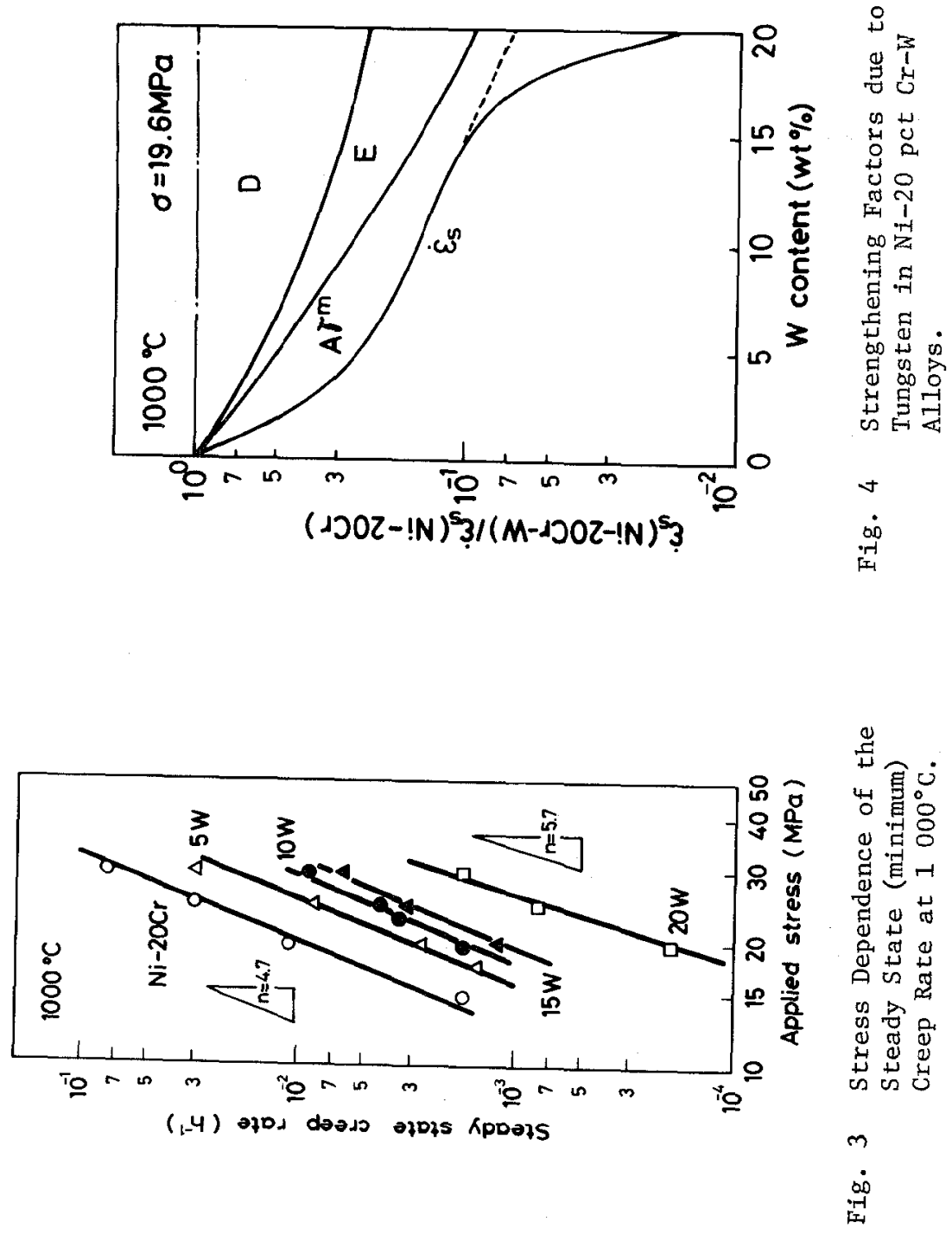


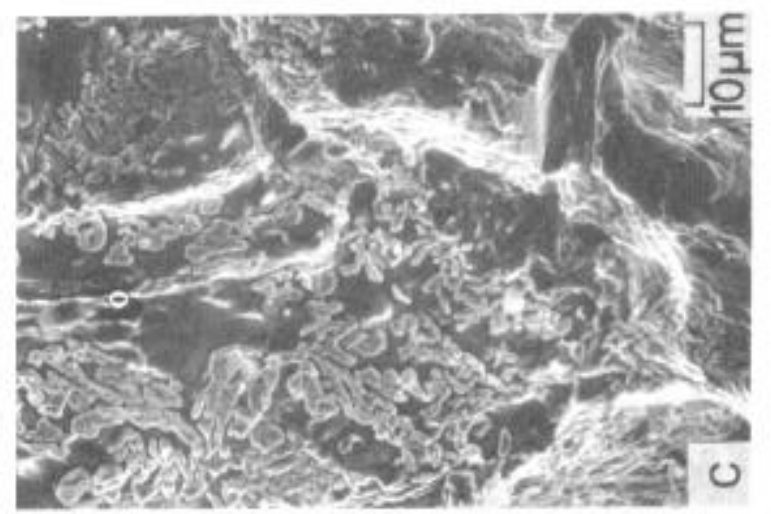

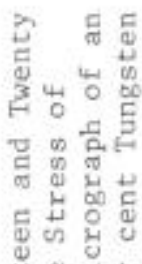

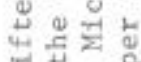
돈 至。

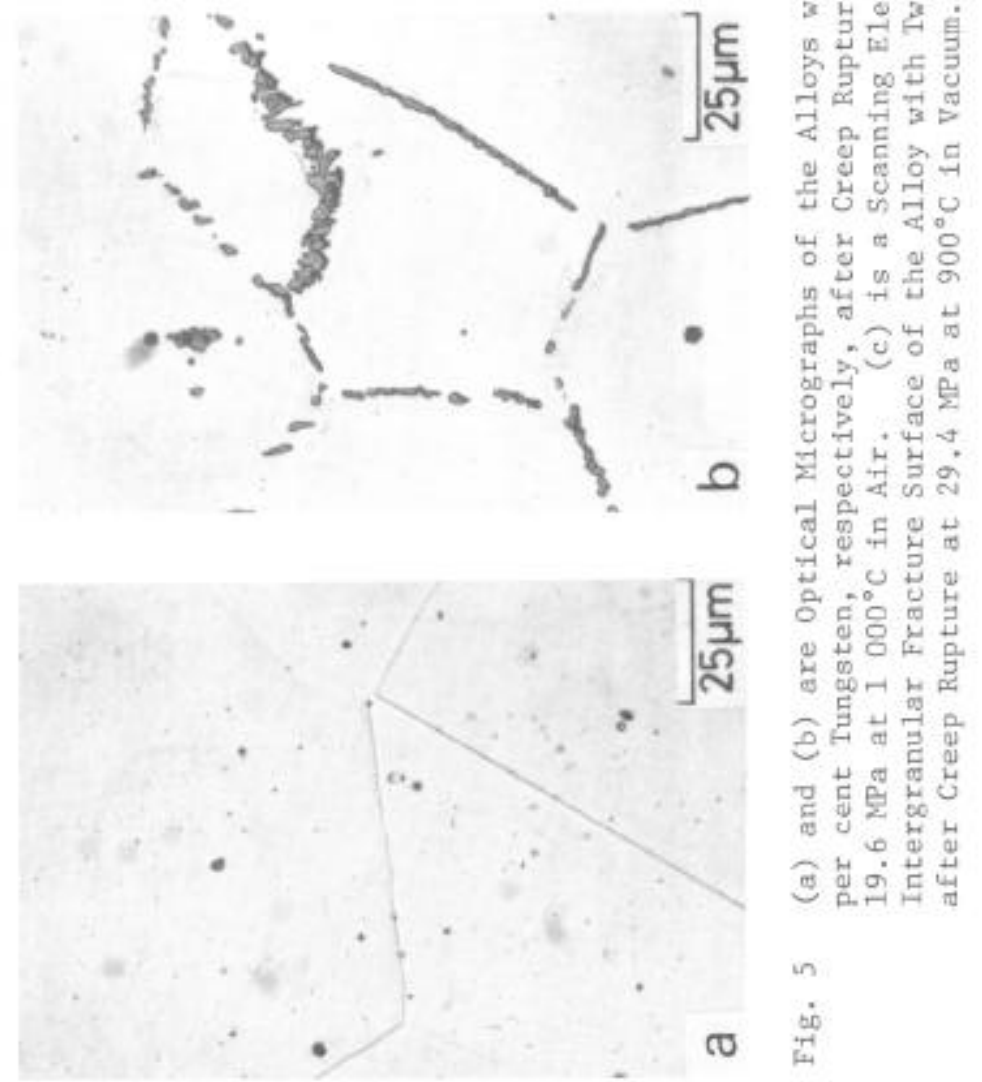

3 녹욜 
490 / Superalloys 1980

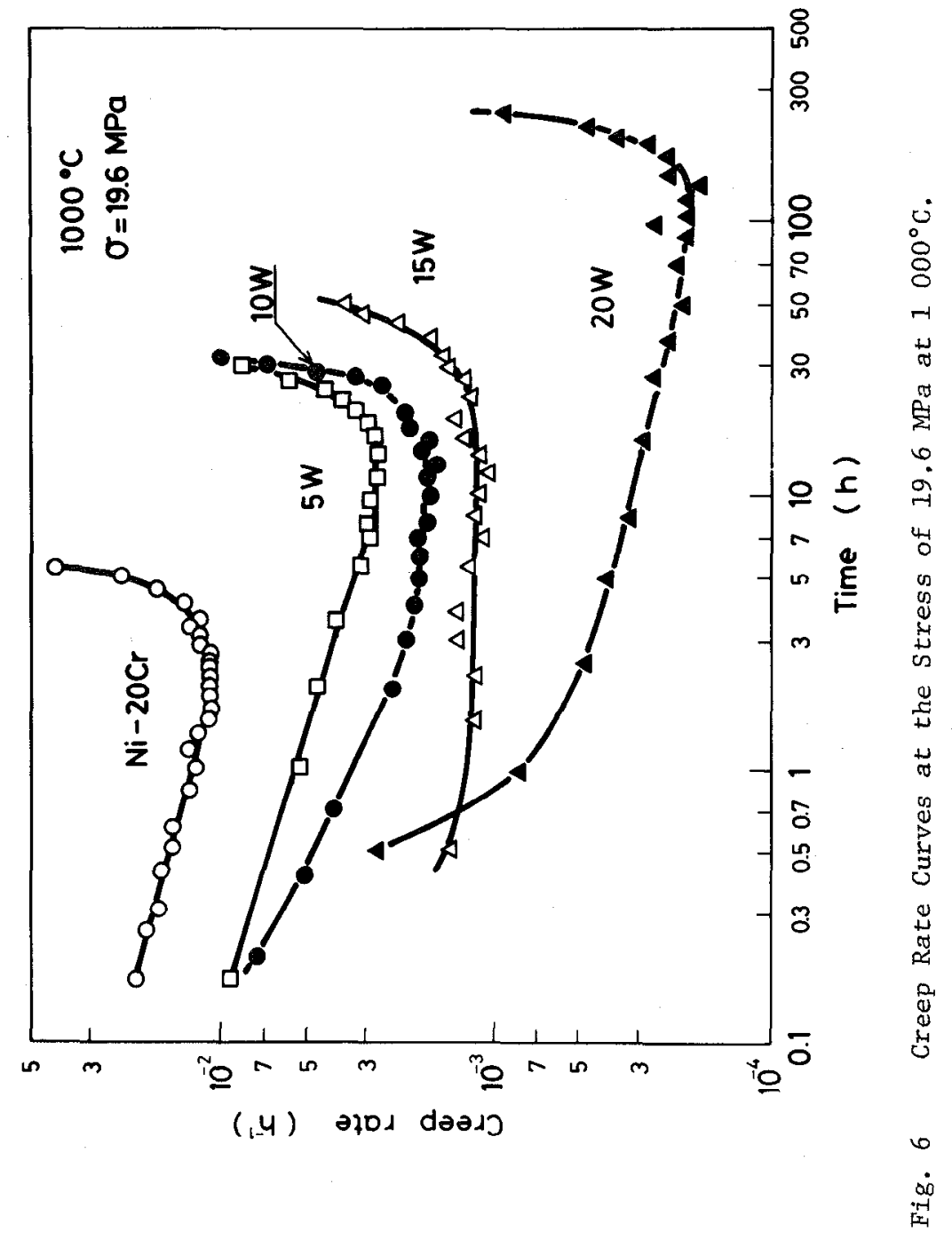

